\title{
The role of evaluation in supporting action on a hazardous world, a call for critical- systems thinking
}

\section{Mat Walton and Virginia Baker}

\begin{abstract}
A commentary on "Confronting storms, fires, and pestilence: Meaningful evaluation for a hazardous world" by Juha I. Uitto (2021).
\end{abstract}

In the article "Confronting storms, fires, and pestilence: Meaningful evaluation for a hazardous world", Juha I. Uitto (2021) provides a stark assessment of many challenges and problems facing humanity across the globe. As well as COVID-19, issues include mass extinction, biodiversity loss, climate change, and persistent social inequity. Uitto lays a challenge at the feet of evaluation to contribute more to generating positive action on these complex problems. Current evaluation practices are considered too often focused on symptoms rather than causes, on internal programme efficiency rather than impact, and on incremental rather than transformative change.

In this commentary we support and take up the challenge laid out by Uitto when concluding that evaluation can make a greater contribution by encompassing 
a systems approach that incorporates across the perspectives of social and natural sciences, paying attention to cultural diversity. Evaluation must focus on learning, from previous interventions and evaluation, and build upon existing knowledge from science. It must also learn from Indigenous knowledge around the world and to assume a holistic perspective to ecosystems and human health ... (Uitto, 2021)

While calling for a "systems approach" Uitto is silent on what type of systems approach. We outline the value of systems approaches drawing upon critical systems, which pay attention to the boundary of programmes within wider contexts of "messy" situations; system behaviour over time; and understanding multiple perspectives in defining the evaluand and criteria for valuing in evaluative judgements.

\section{Wicked problems and critical systems}

Much of the problems described by Uitto fit the definition of "wicked" problems, a phrase coined by Rittel and Webber (1973). Here they use the term wicked

in a meaning akin to that of 'malignant' (in contrast to 'benign') or 'vicious' (like a circle) or 'tricky' (like a leprechaun) or 'aggressive' (like a lion, in contrast to the docility of a lamb). We do not mean to personify these properties of social systems by implying malicious intent. But then, you may agree that it becomes morally objectionable for the planner to treat a wicked problem as though it were a tame one, or to tame a wicked problem prematurely, or to refuse to recognize the inherent wickedness of social problems. (p. 161)

Dimensions of wicked problems described by Rittel and Webber are those where the issue is continually evolving; have multiple causal contributions; and where solutions can only be thought of as better or worse, rather than right or wrong (Rittel \& Webber, 1973). Humans 
are implicitly part of the problem, and possible solutions. Solutions may work, but may also create unanticipated consequences, or simply transfer the problem elsewhere. Systems thinking has often been suggested to inform action with wicked problems (Innes \& Booher, 2010; Ison \& Straw, 2020; Signal et al., 2013).

Such a conceptualisation of wicked problems and systems thinking appears to encapsulate the issues identified by Uitto. For intervention design, these types of problems are best understood as continually evolving issues and interventions as "events in the system" (Hawe et al., 2009), thus rejecting the notion that a simple or single intervention is adequate in generating change. In the face of multiple and interacting causes of a situation, programmes and interventions have a tendency to focus on symptoms rather than causal mechanisms. Particularly when underlying paradigms of thought, such as limitless growth and economic prosperity through increasing consumption may underpin much of the interactions and system-level behaviour. As Meadows notes, addressing paradigms is the hardest place for intervention, even though they may be the most effective at generating change (Carey \& Crammond, 2015; Meadows, 2008). Uitto also highlights the need to understand different interests and perspectives on an intervention. If we consider that "wicked" problems are better or worse, rather than right or wrong, it highlights the need to incorporate different perspectives within evaluative criteria-from whose perspective is an intervention seen as better or worse? Critical reflection on power is crucial and requires attention to history to better understand the present.

Each of the systems ideas mentioned above (interventions as events in systems; understanding multiple and interacting causation and multiple perspectives in evaluative criteria) will be further elaborated. As an overall framework to bring ideas together, we draw upon critical-systems thinking (Jackson, 2019). We reference examples, 
mostly from health and social service areas, where critical-systems approaches have been used within evaluation. The examples are chosen to illustrate different applications of critical-systems thinking within evaluation and are those we are most familiar with. As such, we make no claim that examples are exhaustive of critical-systems informed evaluation.

Critical systems is a grouping of theory and methods within systems thinking that places emphasis on fairness and power of those potentially disadvantaged in a situation, or intervention. These methods strengthen voice and bring multiple values to decisions (Jackson \& Sambo, 2020). Critical-systems approaches are characterised by pluralism and draw on combinations of systems approaches attuned to the importance of understanding a problem from multiple vantage points. Critical systems also seek to support identification and implementation of interventions, an example being the systemic intervention approach (Midgley, 2000).

\section{Programmes as events in a system}

Uitto suggests that evaluation needs to look outside of the internal logic of a programme, which itself should pay attention to root causes of issues, rather than just symptoms. We agree and see this issue as one of how boundaries are understood of the programme and wider environment or system within which is sits. As mentioned above, Hawe and colleagues suggest that programmes are seen as "events in the system" (Hawe et al., 2009). This suggests that the internal logic of the programme should pay attention to the wider system it sits within, while the focus of evaluation would include a view of how the programme and wider system influence each other.

An example of paying attention to the wider system is presented by Foote and colleagues in seeking to measure change in family violence as a whole system (Foote et al., 2015). A system-dynamics model 
of the family violence system was generated from which a series of indicators were developed that pay attention to feedback loops and delays within the system. The suggestion was not to use indicators as measures of performance. Instead, the indicators were to be looked at together by a group of people across the system to jointly make sense of what change may be occurring across the whole system of family violence. Evaluation of a particular programme could then be understood in the context of overall system changes.

\section{A focus on boundaries}

From a critical-systems perspective, the boundaries defining the programme from the wider system, and boundaries defining that wider system, are not fixed but constructed by those with power in design and implementation of a programme. Likewise, the boundaries of the evaluation are not fixed. Gates (2018) discusses the use of critical-system heuristics as one way to consider defining the boundaries of the evaluand. Perspectives on boundaries are intrinsically linked with knowledges, experiences, and values, meaning that valuing within evaluative judgements is also intrinsically linked with how boundaries are set around a programme and understanding of the wider system within which the programme sits. One role of evaluation may be to make explicit how boundaries have been drawn around programmes and the evaluand. If solutions to wicked problems are on a continuum of better or worse, then different perspectives may judge programmes differently on this continuum.

Hepi and colleagues (2021) discuss the use of exploring boundaries using kaupapa Māori evaluation and critical-systems thinking within a partnership between Hauora Hokianga, hapū, and the Institute of Environmental Science and Research (ESR). They discuss how paying attention to boundaries of projects funded by central government agencies supported programmes moving to be more inclusive of hapū 
perspectives and aspirations. Here the design of the programme itself changed, and with it criteria for evaluative judgements.

\section{Understanding system change}

Uitto suggests that evaluation is too focused on internal logic and working of programmes, and that programmes are too often seen as the agent of change. If programmes are seen as "events in systems", and that the boundary between the programme and wider system is constructed rather than fixed, then programmes should be designed within a theory of wider systems change. From a critical-systems perspective, systems change will occur through ongoing purposeful and systemic action, with ongoing reflection on the situation from multiple perspectives. Through such reflection on boundaries, underlying mental models, or paradigms will be exposed, which creates opportunity for change (Carey \& Crammond, 2015; Kania et al., 2018). As Uitto notes, root causes of many wicked problems are related to paradigms such as consumerism and the environment as an input into economic processes. Paradigms shape policies, processes, and resources that then shape system behaviour over time. Evaluation processes can highlight both paradigms and resulting system structures and conditions in order to inform systems-change activities.

The whole-system evaluation of family violence described above again provides an example of evaluation to support systems change. Drawing upon system dynamics, there was a theory of how change in acts of family violence and service responses develop over time. While data could be collected as indicators against this theory of change, just as important was purposeful engagement of diverse perspectives to make sense of the data and suggest areas for further action.

The evaluation of Healthy Families NZ provides another example. The design of Healthy Families NZ included a theory of creating systems change through community-level action for health. Because 
communities are different, there was an assumption that activities would also be different across communities. The evaluation used a case-comparison approach to first understand experience in each community, then compare across communities to highlight how specific contexts interact with programme design (Matheson et al., 2017; Matheson et al., 2020).

Gates and Fils-Aime (2021) discuss the role of evaluation in supporting health-related systems-change efforts of the Rippel Foundation. They describe how developmental and realist evaluation frameworks are used, orientating evaluation to be a learning tool that supports ongoing critical reflection on how the problem situation is understood; design of programmes; and conditions for systems change.

Understanding conditions for systemic evaluation and research practices is highlighted by Goven and colleagues in the Kaikoura Biowaste Project (Goven et al., 2015); and by Foote and colleagues in evaluation of community environmental-management programmes (Foote et al., 2021). These studies highlight that effectiveness of a critical-systems approach to evaluation requires enabling relationships that support engagement of diverse perspectives and action on findings.

\section{Conclusion}

Uitto joins others in raising the need for urgent responses to global warming and other cumulative symptoms and consequences of underpinning paradigms of global economics, production, and consumption. There is no doubt the world is facing a number of complex and interacting wicked problems, including climate change, biodiversity loss, continued economic and health inequity, to name a few. Economic systems built upon increasing consumption are common contributors to these issues. A contributor to our inability to 
resolve wicked problems is marginalisation of alternative paradigms of understanding and valuing; for example, Indigenous knowledge and its attention to holism and connection to place and environment. We agree with Uitto that evaluation can play a greater role in designing more effective transformative action. To do this, evaluation will need to support programmes and interventions to locate activities within wider systems change, to reflect and challenge boundaries and include other viewpoints and values in design of programmes and evaluative activities. Uitto suggests that evaluation needs to utilise multi- and interdisciplinary systems approaches. We agree and have sought to highlight the contribution that critical-systems thinking and methods can make to such an endeavour. In doing so, we hope to extend the discussion from what the role of evaluation can be, to a focus on how evaluation can support action on wicked problems. We suggest that critical systems provides an orientation that supports action by being inclusive of the values and viewpoints of those who are most impacted by the problems, and thus providing an opportunity to question and alter the paradigms required for transformative change.

\section{References}

Carey, G., \& Crammond, B. (2015). Systems change for the social determinants of health. BMC Public Health, 15(1), 10.

Foote, J., Carswell, S., Wood, D., \& Nicholas, G. (2015). Measuring the effectiveness of 'whole-of-system' response to prevent family violence. Social Policy Evaluation and Research Unit. http://www.superu.govt.nz/ publication/measuring_whole_of_system_report

Foote, J., Midgley, G., Ahuriri-Driscoll, A., Hepi, M., \& Earl-Goulet, J. (2021). Systemic evaluation of community environmental management programmes. European Journal of Operational Research, 288(1), 207-224. https://doi.org/10.1016/j.ejor.2020.05.019 
Gates, E. F. (2018). Toward valuing with critical systems heuristics. American Journal of Evaluation, 39(2), 201-220. https://doi. org/10.1177/1098214017703703

Gates, E. F., \& Fils-Aime, F. (2021). System change evaluation: Insights from the Rippel Foundation and its ReThink Health initiative. New Directions for Evaluation, 125-138. https://doi.org/10.002/ev.20462

Goven, J., Langer, E. R. L., Baker, V., \& Ataria, J. (2015). A transdisciplinary approach to local waste management in New Zealand: Addressing interrelated challenges through indigenous partnership. Futures, 73, 22-36. https://doi.org/10.1016/j.futures.2015.07.011

Hawe, P., Alan, S., \& Riley, T. (2009). Theorising interventions as events in systems. American Journal of Community Psychology, 43, 267-276. https:// doi.org/10.1007/s10464-009-9229-9

Hepi, M., Foote, J., Ahuriri-Driscoll, A., Rogers-Koroheke, M., Taimona, H., \& Clark, A. (2021). Enhancing cross-cultural evaluation practice thorugh kaupapa Māori evaluation and boundary critique: Insights from Aotearoa New Zealand. New Directions for Evaluation, 51-65. https://doi. org/10.1002/ev.20457

Innes, J. E., \& Booher, D. E. (2010). Planning with complexity: An introduction to collaborative rationality for policymaking. Routledge. https:// doi.org/10.4324/9780203864302

Ison, R., \& Straw, E. (2020). The hidden power of systems thinking: Governance in a climate emergency. Routledge. https://doi.org/10.4324/9781351026901

Jackson, M. C. (2019). Critical systems thinking and the management of complexity. Wiley.

Jackson, M. C., \& Sambo, L. G. (2020). Health systems research and critical systems thinking: The case for partnership. Systems Research and Behavioral Science, 37(1), 3-22. https://doi.org/10.1002/sres.2638

Kania, J., Kramer, M., \& Senge, P. (2018). The water of systems change. https://www.fsg.org/publications/water_of_systems_change

Matheson, A., Walton, M., Gray, R., Lindberg, K., Shanthakumar, M., Fyfe, 
C., ... Borman, B. (2017). Evaluating a community-based public health intervention using a complex systems approach. Journal of Public Health, 1-8. https://doi.org/10.1093/pubmed/fdx117

Matheson, A., Walton, M., Gray, R., Wehipeihana, N., \& Wistow, J. (2020). Strengthening prevention in communities through systems change: Lessons from the evaluation of Healthy Families NZ. Health Promotion International, 35(5), 947-957. https://doi.org/10.1093/heapro/daz092

Meadows, D. H. (2008). Thinking in systems: A primer. Sustainability Institute.

Midgley, G. (2000). Systemic intervention: Philosophy, methodology, and practice. https://doi.org/10.1007/978-1-4615-4201-8

Rittel, H. W. J., \& Webber, M. M. (1973). Dilemmas in a general theory of planning. Policy Sciences, 4(2), 155-169. https://doi.org/10.1007/ BF01405730

Signal, L., Walton, M., Ni Mhurchu, C., Maddison, R., Bowers, S., Carter, K., . . Pearce, J. (2013). Tackling 'wicked' health promotion problems: A New Zealand case study. Health Promotion International, 28(1), 84-94. https://doi.org/10.1093/heapro/das006

Uitto, J. I. (2021). Confronting storms, fires, and pestilence: Meaningful evaluation for a hazardous world. Evaluation Matters_He Take Tō Te Aromatawai, 7.

\section{The authors}

Mat Walton (corresponding author)

Virginia Baker Institute of Environmental Science and Research (ESR), Porirua, New Zealand

Email: mathew.walton@esr.cri.nz 